\title{
AS KHARITES EM TORNO DO PODER FEMININO. SABER E LINHAGEM
}

\author{
María Cecilia Colombani ${ }^{1}$
}

\begin{abstract}
Resumo
O objetivo do presente trabalho é determinar a função do discurso mítico no trabalho hesiódico como um operador que institui um universo de significados que se encontra entre o mito. Nossa hipótese é que, no trabalho hesiódico, certas imagens conceituais se encontram, principalmente as da linhagem, que definem o campo do Mesmo e do Outro. Nesse contexto, pretendemos analisar a figura das Khárites associada à das Musas como poderes religiosos para ler formas de poder feminino a partir de um certo tipo de conhecimento que se desdobra em ambos os grupos.
\end{abstract}

\section{Palavras-chave}

Mito, Khárites, Musas, Poder, Conhecer, Linhagem.

1 Professora Doutora - Universidad de Morón, Morón, Argentina. E-mail: ceciliacolombani@hotmail.com 


\section{Resumen}

El objetivo del presente trabajo es determinar la función del discurso mítico en la obra hesiódica como un operador que instituye un universo de sentido que se encuentra entre el mito. Nuestra hipótesis es que en la obra hesiódica se encuentran ciertas imágenes-conceptuales, principalmente las del linaje, que definen el campo de lo Mismo y de lo Otro. En este marco pretendemos analizar la figura de las Khárites asociada a la de las Musas como potencias religiosas para leer formas del poder femenino a partir de un determinado tipo de saber que se despliega en ambos colectivos.

\section{Palabras clave}

Mito, Khárites, Musas, Poder, Saber, Linaje. 


\section{Introdução ${ }^{2}$}

O objetivo do presente trabalho é determinar a função do discurso mítico na obra hesiódica como um operador que institui um universo de sentido que se encontra entre o mito. Nossa hipótese é que na obra hesiódica se encontram certas imagens-conceituais, principalmente as da linhagem, que definem o campo do Mesmo e do Outro. Neste marco pretendemos analisar a figura das Khárites associada à das Musas $^{3}$ como potências religiosas para ler formas do poder feminino a partir de um determinado tipo de saber que se espalha em ambos coletivos.

Seguindo a Foucault no marco de seu período arqueológico, entenderemos ao mito como uma forma de discurso, isto é, como um operador da verdade que determina relações de poder-saber. $O$ objetivo é identificar no discurso hesiódico as estruturas internas de certas coordenadas antropológicas: o divino e o humano, o noturno e o luminoso, o humano e o animal, o masculino e o feminino. Trata-se de reconstruir as estruturas discursivas que definem isto para entender que é parte de uma determinada configuração de época, um magma de significações que se está erigindo, brotando, irrompendo, desde as próprias ruínas da configuração mítica; trata-se de acompanhar o discurso hesiódico para ver como impulsiona um novo ê̂dos, uma nova ideia de homem, de mundo, de natureza.

O discurso abre o campo de emergência de uma determinada forma de ver e de nomear a realidade. Outorga as regras de formação que travam as palavras e as coisas e a lógica da linhagem é precisamente a ferramenta que permite a tarefa interpretativa. Não só define que se vê e que se diz, mas também como se articula junto com as práticas sociais.

Devemos abordar a configuração mítica como um modo de realçar sua lógica dominante, onde, como Detienne demonstrou (1986: 145-148)4, a noção de ambiguidade tensiona a dupla alétheia-léthe, sem que o par implique um jogo contraditório que se auto-exclua. $\mathrm{O}$ desvelado e o velado convivem no interior de um pensamento não cerceado ainda pela tirania

\footnotetext{
${ }^{2}$ A presente introdução faz parte de minha tese doutoral publicada com o título Hesíodo. Discurso e Linhagem. Uma aproximação arqueológica (2016). Efetuaram-se revisões do original.

${ }^{3}$ Para uma análise exaustivo da entidade das Musas, veja-se Brandao (2005).

${ }^{4}$ A totalidade da obra dá conta de como se opera a declinação desta província do mágicoreligioso para possibilitar a abertura de um tópos que albergue a experiência do lógos como lógica triunfante, como o novo modo de olhar e nomear o mundo.
}

Heródoto, Unifesp, Guarulhos, v. 4, n. 1, 2019.1 p. 196-212

DOI: https://doi.org/10.34024/herodoto.2019.v4.10111 
de uma lógica alethés-pseudés, em um tópos irreconciliável desde o extremo cuidado da não contradição, como perigo capital.

O campo mítico, articulado na província do mágico religioso, reconhece diferentes territorialidades onde opera vigorosamente um pensamento subtendido por esta lógica: o campo poético, o mântico e o da soberania. Tangencialmente e como modo de situar a Hesíodo no imaginário de sua época, nos propomos abordar o texto hesiódico a partir de um horizonte vinculado à noção de arkhé. Trata-se de pensar a solidariedade entre pensamento e poder, entendendo que o pensamento opera como um instrumento de legitimidade de condutas, instituições e valores. O mito é uma usina produtora de sentido e nesse marco constitui uma estrutura de poder, impõe um lógos dominante, uma olhada-experiência sobre o real, que só uma nova experiência de saber-poder terá de fraturar, despregando um novo $\log o s^{5}$.

Sem dúvida, a dimensão do poder radica precisamente nesta capacidade poética que articula efeitos sobre a realidade. $\mathrm{O}$ mito possui então um efeito político transformador do próprio real. É um discurso que delineia o campo da Verdade.

O que mantém em cena, remarcando a metáfora teatral, uma explícita configuração de pensamento é o vigor das forças que determinaram sua emergência e que a sustentam; a saber, o mito, como estrutura de pensamento, e Hesíodo, constituem, segundo Detienne (Hesíodo, 1986: 28), os últimos testemunhos desse tipo de palavra. A deslocação dá-se então pelo próprio enfraquecimento dessas forças que se esgotam, enclausurando o modelo ficcional ${ }^{6}$.

Agora vamos nos concentrar no que constitui o outro pilar sobre o que se assenta nossa perspectiva de pensar a Hesíodo como uma novidade. Referimo-nos à lógica da linhagem presente em seus poemas. Esse tem sido sem dúvida o elemento de coesão de nosso trabalho porque tem

\footnotetext{
${ }^{5}$ Seguimos nesta tentativa de leitura as indicações de Michel Foucault (1979) sobre a união entre saber e poder como modo de travar a relação que guardam as palavras e as coisas em um determinado momento histórico. O saber não é senão uma estrutura de poder que legitima o colocar em funcionamento desse saber produzido historicamente. ${ }^{6}$ Foucault (1979). Na conferência "Nietzsche, a história, a genealogia" o autor aborda a tensão Ursprung-Erfindung, origem-emergência, percorrendo a letra nietzscheana. Propõe-se a dimensão da emergência do acontecimento a partir das forças que o possibilitam por sobre a imagem estática da origem, a-histórico e não contaminado com os avatares da história. Foucault está mergulhando na genealogia nietzscheana um novo modo de pensar o acontecimento no marco das condições possíveis, que são sempre de caráter histórico-deveniente e não substancial.
}

Heródoto, Unifesp, Guarulhos, v. 4, n. 1, 2019.1 p. 196-212

DOI: https://doi.org/10.34024/herodoto.2019.v4.10111 
constituído a novidade em Hesíodo. Já temos definido à linhagem como o operador discursivo que dá coerência a essa totalidade, que avança para formas mais justas e ordenadas, tanto no plano cósmico-divino como no plano social; forma mais ordenada na medida em que a linhagem positiva triunfa estruturalmente sobre o negativo.

Ficam delineados nos dois poemas dois territórios conceituais que permitem classificar essa totalidade que incorpora tanto ao mundo natural como ao humano em um sistema de significação compacto. Isto não implica que não apareçam ambiguidades e misturas, bifurcações e atalhos, não obstante, tomam um perfil claro que nos permite sua utilização como operadora discursiva e de sentido.

Este diagrama de forças que as linhagens representam, constitui a chave que possibilita as ambições de Hesíodo,

Ambições por assim o dizer unitárias: essas grandes e complexas descrições que, ademais, ao menos no caso dos dois primeiros poemas, representam uma visão idealizada: o progresso do mundo consiste na implantação da ordem de Zeus, que garante a justiça (Rodríguez Adrados, 2001: 199).

Efetivamente, para que essa ordem se dê nos termos da sucessão cronológica que a Teogonía apresenta ou da implementação sócio-histórica que os Érga propõem, é necessária a lógica da linhagem.

Deste modo, o dispositivo da linhagem inscreve-se nos dois poemas como articulador de sua unidade. A unidade radica na progressiva organicidade dos sistemas, o cósmico, o divino e o humano, e essa ordem que vão construindo, não sem conflito nem tensões, exige a presença de certos operadores que delimitem os espaços sobre os quais se assenta toda organização, o diurno e o noturno, o positivo e o negativo, o aceitável e o rejeitável, o legal e o ilegal, o justo e o injusto; em última instância, a tensão de opostos que dá conta do gérmen mesmo do real em seu conjunto. Potências e divindades que estão inscritos em uma ou outra linhagem, reis, homens, mulheres, instituições, comportamentos, estilos de vida, cidades, que podem ser lidos de uma perspectiva ou outra. Complexidade que se joga na dimensão agonística dos oponentes em conflito, que representa um claro antecedente de formulações posteriores que fazem do pólemos o fio que tece a constituição da realidade.

Heródoto, Unifesp, Guarulhos, v. 4, n. 1, 2019.1 p. 196-212

DOI: https://doi.org/10.34024/herodoto.2019.v4.10111 


\section{As Khárites}

"Las Chárites, divinidades de la palabra, del mito cantado" (Bermejo Barrera, 1996: 63)

À luz do que foi dito acima, vamos parar agora para analisar as Khárites a fim de colocá-las nessa espessura mítica e na linhagem diurna a partir de suas marcas de identidade. Apenas alguns dados que serão, então, problematizados. As Khárites são filhas de Zeus e Eurínome. Em princípio, são divindades da vegetação que mais tarde se tornam divindades de beleza.

Irmãs das Moûsai, sua residência é no Olimpo, ao lado das nove deliciosas filhas da deusa Mnemosýne, que marca seu parentesco luminoso; também nas proximidades é a morada de Deseo, o companheiro frequente de Afrodite. A proximidade é inscrita numa proximidade de identidade, além de geográfica. A referência feminina é tocada em uma constelação luminosa: as Moûsai, as Khárites e a própria Afrodite. A influência atribuída a elas nas tarefas do espírito e das obras de arte completa sua pertença a uma linhagem positiva e diurna. Constituem a personificação de valores positivos como o júbilo, personificada por Aglaya, prazer, por Eufrósina e felicidade, por Talía. Os atenienses só conhecem duas Khárites, ambas associadas à vegetação: Auxo, aquela que faz as plantas crescerem, e Hegemoné, aquela que guia as plantas para fora do solo. Na verdade, elas foram reverenciadas com a intenção de que as colheitas fossem abundantes.

Orcómeno, cidade da Beócia, fundada pelo rei Minias, era o local de culto mais famoso e seu templo era muito próximo ao destinado a Dioniso, perto de uma fonte consagrada à deusa Afrodite. Seu culto era a proliferação de ritos muito antigos, próprios de Orcómeno. O símbolo com o qual estão associados são três grandes pedras caídas do céu no tempo do rei Etéocles.

As Caritesias eram as festividades dedicadas às divindades e as conhecemos por inscrições. Eles incluíam aspectos musicais e danças que ocorreriam durante a noite; compreendiam concursos de tragédia e comédia, onde os jogadores de flauta ou cítara rivalizavam entre si. Então, a associação com as artes também é clara. Mas além dessas notícias gerais, nossa intenção é colocá-las no contexto hesiódico e nas projeções que elas terão em outros autores, como por exemplo, Píndaro.

Vamos ao texto para ver sua apresentação e sua linhagem matriz diurna a partir de de sua gloriosa mãe.

Heródoto, Unifesp, Guarulhos, v. 4, n. 1, 2019.1 p. 196-212

DOI: https://doi.org/10.34024/herodoto.2019.v4.10111 


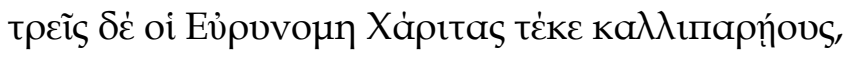

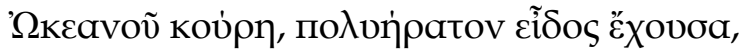

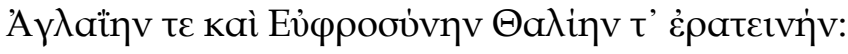

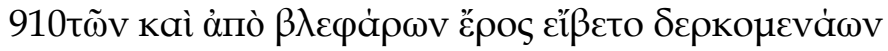

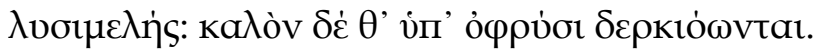

Tres Cárites le dio a luz Eurínome de hermosas mejillas,

hija de Océano de muy delicioso aspecto:

Aglya, Eufrósine y Talía agradable;

de sus ojos penetrantes se derrama el amor

que afloja miembros; bellamente bajo las cejas miran penetrante. (Teogonía, 907911).

Como vemos, as Khárites são o fruto do amor entre Zeus e Eurynome. Uma marca remete ao encanto das três meninas, enfatizado pelo adjetivo

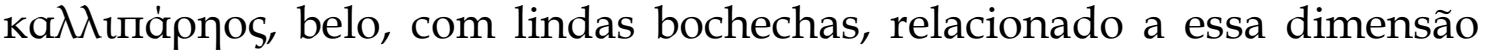
estética com as Musas que desfrutam do mesmo encanto de sua juventude e beleza.

Sua mãe também é referida com um adjetivo de valoração positiva,

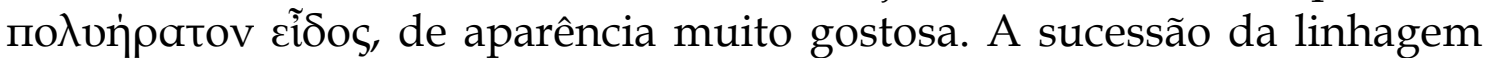
entre mãe e filhas é, portanto, semelhante à linha que liga as musas hesiódicas com à sua Mãe gloriosa, Mnemosyne e pertença a um universo feminino de origem diurna.

As Khárites estão diretamente ligadas ao Eros como força de coesão; são elas que derramam amor. O campo léxico do verbo ciß $\beta \omega$, derramar, verter, fala de sua generosa capacidade de prover amor, épos. É ele quem solta os

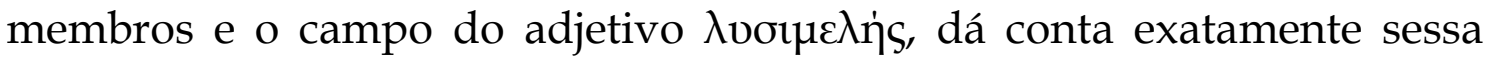
condição.

Finalmente, são elas que olham com olhos penetrantes, destacando sua beleza. Mas agora, a dimensão espacial das Khárites merece algumas considerações que afetam diretamente nosso projeto de leitura. É a contiguidade com as Musas que gera uma condição muito particular que começa sendo espacial e depois tem outras derivações.

Tal como sustenta Calame:

Heródoto, Unifesp, Guarulhos, v. 4, n. 1, 2019.1 p. 196-212

DOI: https://doi.org/10.34024/herodoto.2019.v4.10111 
Las musas hesiódicas, encarnación de la poesía arcaica, producen - ¿es preciso recordarlo? - en las cercanía de Hímero y de las Chárites una melodía cantada y un ritmo de danza cuyo eco suscita el éros, cualidad personificada en el nombre mismo de la Musa Erato, que despierta el deseo (Calame, 2002: 53).

É esse grupo de poderes ligados à beleza e amor ao qual queremos direcionar nossa análise. Vamos começar com o sinal de proximidade e familiaridade que as coloca na mesma série de luz e dia. De fato, junto com as filhas bem-faladas de Zeus, Hímero e as Khárites têm suas casas, oỉi' Ě Xovorv, percebendo o mesmo tópos que abriga elementos de valência positiva. É essa associação, especialista em questões de amor, a que “Teognis pone en boca de las Musas y las Chárites (Gracias) para celebrar las bodas de Cadmo y de Armonía, nacida de la unión de Ares y de Afrodita" (Calame, 2002: 126).

Se retornarmos ao poema hesídico, a vizinhança do grupo não é apenas espacial. A contiguidade geográfica faz parte de uma aliança funcional. Bermejo Barrera estende a associação para a mesma função, geralmente reservada para as Musas. O autor indica ao grupo como criadores da música, sendo que os três versos que considera interpolados, "se dice que cantan en las fiestas las leyes y alaban los sabios principios comunes a todos los inmortales" (1996: 60). Brincando com essa interpretação amplia a função comemorativa e esse grupo associado ao amor e ao charme constituiria uma estrutura de poder do conhecimento no âmbito da economia olímpica.

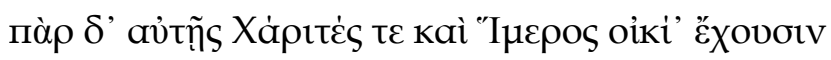

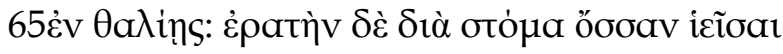

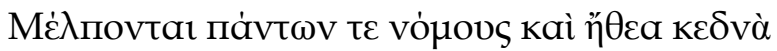

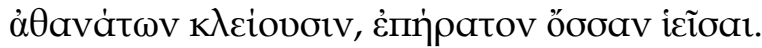

y junto a ellas las Cárites y también Hímero tienen sus casas;

en los banquetes, emitiendo su amable voz por la boca,

cantan las leyes de todos, y las costumbres respetables

de los inmortales celebran, emitiendo su muy amable voz. (Teogonía, 64-67).

A primeira coisa que aparece é uma coexistência nos banquetes, દ̇v $\theta a \lambda i n \varsigma$, inscrevendo a função comemorativa na estrutura festiva apropriada à palavra de louvor. O uso do particípio, i̇̃ođat, dá conta da função do campo

Heródoto, Unifesp, Guarulhos, v. 4, n. 1, 2019.1 p. 196-212

DOI: https://doi.org/10.34024/herodoto.2019.v4.10111 
lexical do verbo, derramar, verter, emitir, deixar ouvir. Esta ação é complementar ao seguinte verso, inscrevendo o campo lexical do verbo $\mu \varepsilon \dot{\lambda} \Pi \omega$, celebrando com dança e canto, cantar e dançar, em uma função festiva que as coloca no campo da beleza e charme como marcas de identidade. As lindas damas emitem sua voz imortal, öooav, dando conta de um tipo de conhecimento que as coloca em um tópos de poder.

Como Bermejo Barrera discute, "en estos versos las Gracias son sinónimos de las Musas, y uno de los caracteres básicos de ese grupo de mujeres era el cantar el orden olímpico y sus principios" (1996: 61). Esta é a chave para a associação proposta pelo autor e o valor da função comemorativa como a revelamos. É uma força feminina a serviço da conservação da ordem cósmica. Se mais tarde o poeta vai se tornar um "oficial de soberania" ao narrar a criação ao mesmo tempo em que o rei mima o combate fundador que estabelece a soberania cósmica (Detienne, 1986: 21-38), nesse nível da história mítica, o coletivo feminino cumpre uma função análoga, servindo com sua voz divina, ő $\sigma a$, a Zeus, o fiador da ordem cósmica. É uma função chave na ordem cósmica que também explica uma linha de sucessão entre as Khárites e sua mãe Eurínome, a Boa Ordem.

Reaparece então uma linha direta na sucessão de uma linhagem diurna que, de mãe para filha, dá conta de um conhecimento que colabora diretamente com o Soberano em sua realidade organizadora. Nós concordamos com Bermejo quando ele afirma,

El canto de este coro está pues en Hesíodo asociado a los principios legales y al orden cósmico, transmitidos a Zeus a través de su matrimonio anterior. La asociación de las Chárites con el orden del mundo, con los reyes y la Función, deriva en parte del propio carácter de su madre Eurínome" (1996: 61).

As coincidências atingem, assim, a linha ascendente da linhagem materna. As Musas herdam da mãe a maravilhosa voz associada à Memória sacralizada, aquela que sabe o que foi, o que é e o que será. Mnemosyne é uma onisciência de caráter divinatório que permite a suas filhas cantar a glória do Pai. As Khárites recebem uma função análoga de sua mãe; uma dimensão comemorativa que coloca a ordem e a legalidade no centro da cena. Dupla estrutural onde Mnemosyne é para o Eurínome o que as Musas são para os Khárites. De mães a filhas, é instituída uma função que celebra e louva uma força cósmica.

A escolha de Zeus em relação às suas mulheres merece alguma consideração. Mnemosyne deu a ele nove filhas deliciosas que o celebram e mantêm seu nome associado à soberania. Eurínome forneceu-lhe tantas outras filhas que, associadas à primeira, constituem um coletivo também

Heródoto, Unifesp, Guarulhos, v. 4, n. 1, 2019.1 p. 196-212

DOI: https://doi.org/10.34024/herodoto.2019.v4.10111 
ao serviço da soberania do Pai. Como Bermejo argumenta, "En este matrimonio, como en los anteriores, por consiguiente, Zeus se asocia a una mujer preolímpica que posee un poder indudablemente relacionado con la soberanía" (1996: 61).

Deste modo, ambas as esposas proporcionarão através de suas deliciosas filhas, o poder de cantar, relacionadas à manutenção da ordem soberana que, como sabemos, acaba corroborando o poeta. Portanto, são eles, as Musas, que a escondem com um cetro de loureiro florido para perpetuar sua própria função divina.

\section{Além de Hesíodo}

Em seguida, propomos dar outro testemunho sobre as Khárites para confirmar alguns aspectos identitários e funcionais que temos acompanhado. Em primeiro lugar, vamos trabalhar o XIV Olímpico de Píndaro, provavelmente datado de 488, onde o poeta elogia as deusas. A tradição indica que o próprio poeta dirige em 448 a celebração do triunfo de Ascópico de Orcómeno. É em Orcómeno onde as Khárites têm um santuário e é a elas que Asópico deve seu triunfo no estádio olímpico. Vamos começar com a primeira estrofe

¡Vosotras, que las ondas del Cefiso obtuvisteis

del destino y que habitáis el paraje de hermosos corceles,

Oh Gracias, dignas de ser celebradas en cantos, reinas

de la espléndida Orcómeno, protectora de los Minias antiguos,

Escuchadme, os lo ruego! Pues por vosotras se otorga alegría

y toda dulzura a los mortales,

cuando alguien es sabio o de hermosa figura o famoso.

Porque, sin las Gracias augustas, ni siquiera los dioses

ordenan sus festines y danzas; sino que en el cielo son ellas

servidoras de todas las cosas, ocupando sus tronos

al lado de Apolo Pitio, el del arco de plata,

y adoran la majestad eterna de su Olímpico Padre (1-12). ${ }^{7}$

\footnotetext{
${ }^{7}$ Píndaro, Olímpica, XIV

Heródoto, Unifesp, Guarulhos, v. 4, n. 1, 2019.1 p. 196-212

DOI: https://doi.org/10.34024/herodoto.2019.v4.10111
} 
A semelhança com a invocação das Musas é notória. O poeta se dirige as Khárites, solicitando sua atenção, assim como Hesíodo, do qual se sente como um servo eterno.

As primeiras marcas são de natureza espacial, pois as deusas reinam sobre as ondas do Cefiso, um pequeno rio costeiro que cruzou a Beócia e que, segundo Pausânias em Descrição da Grécia (9.38.7), captando uma tradição tebana, foi desviado por Héracles até o planalto de Orcómeno. Daí a sua relação com a esplêndida "Orquémia", onde o santuário que as celebra com canções é encontrado, assim como as musas são celebradas para a canção eterna do poeta. Protetores dos minas, povo beocio, primeiro a receber um nome entre os pelasgos, localizado em Orcómeno; os dados reforçam seu registro na região, simbolicamente a mesma em que se inscreve Hesíodo.

O parentesco com as Musas está atestado na função festiva: "Pois por vocês se outorga alegria e toda doçura aos mortais". Khárites e Musas estão inscritas na mesma linhagem diurna a partir desta prodigalidade de ternura, doçura e alegria, própria, por outro parte, de sua condição de Filhas de um gloriosíssimo Pai. No caso das Musas esta função de prodigar alegria está diretamente relacionada com uma função terapêutica de acalmar as preocupações dos mortais e dos Imortais. Neste caso a alegria está ao serviço de deleitar aos mortais sábios, de formosa figura ou famosos, isto é, aqueles que se acham inscritos em uma mesma linhagem diurna. Tal como sustenta Bermejo Barreira, são "consideradas como dadoras de todo lo agradable, especialmente del renombre para los hombres" (1996: 64). Como seus afamadas irmãs, as Khárites representam o princípio de inteligibilidade que separa os campos do encantador e agradável daquilo que não o é. Em última instância, são operadoras de sentido e territorializam todo o bom e amoroso em um campo que se erige socialmente como aquilo que se apetece em oposição às figuras de genealogia monstruosa.

Há uma menção interessante em torno de certa dependência dos deuses em relação com elas, já que "sem as Graças augustas, nem sequer os deuses ordenam suas festas e dança". A dimensão funcional fica assim atestada em Píndaro. São as verdadeiras artesãs da alegria dos Imortais ao organizar seus encontros, amenizados por seus dança. Essas "servas de todas as coisas" são figuras femininas de força inegável. É um coletivo poderoso que combina o poder de servir os Imortais com saber como fazê-lo. Sem dúvida, o maior serviço é o louvor da majestade de Zeus, "a majestade eterna de seu Olímpico Pai", e este tópico resulta um novo ponto de encontro com suas diurnas irmãs.

Heródoto, Unifesp, Guarulhos, v. 4, n. 1, 2019.1 p. 196-212

DOI: https://doi.org/10.34024/herodoto.2019.v4.10111 
São as encantadoras filhas que o Pai precisa para manter sua soberania cantada, sua poder eternamente narrado pela maravilhosa voz do canto feminino. Nascimentos funcionais à glória do Soberano onde Mnemosyne e Eurinome cumprem um papel fundamental, se convertendo nas gloriosíssimas damas capazes de reproduzir o que Zeus precisa para garantir e perpetuar seu poder, e com isso assegurar a ordem cósmica e social. Não há glória sem canto. É a mesma lógica que se reflete na condição guerreira. $\mathrm{O}$ mundo divino inaugura um modelo de funcionamento onde o poder do canto gera a glória mesma. A palavra cobra assim uma dimensão ontológica já que outorga o ser do homem cantado.

Duas potências parecem ser temíveis neste marco de pensamento: o Louvor e a Desaprovação. Na verdade, trata-se de duas articulações dominantes da lógica guerreira porque determinam processos de territorialização e desterritorialização, de visibilidade e invisibilidade, de aparecimento e desaparecimento. Inclusive, as duas noções dominantes jogam-se, a nosso entender, em uma metáfora luminosa que determina zonas de luz e escuridão, que recaem diretamente sobre a figura do guerreiro marcando seu reconhecimento e aprovação social ou bem sua desaprovação, articulada em morte. $\mathrm{O}$ homem homérico adquire consciência de seu valor pelo reconhecimento da sociedade à que pertence. É um produto de sua classe e mede sua própria excelência pela opinião de seus semelhantes (Jaeger, 1995: 25). Trata-se de uma lógica que tensiona dois pólos antitéticos: alétheia-léthe. Efetivamente, a aprovação joga-se no horizonte da verdade, como des-oculto, des-velado. A honra tira o véu do opróbrio, desvela e descobre o ser do guerreiro. Pelo contrário, a desonra cobre e esconde o bom nome e fama. O homem é assim obscurecido, coberto por trás do véu do anonimato.

O mesmo dispositivo em que a palavra é o caminho do acesso à verdade. As Khárites mantêm com seu canto o próprio ser da soberania, como fazem as musas e os poetas como oficiais dessa soberania.

A segunda estrofe nos traz novas marcas de identidade que reforçam a territorialização das três irmãs na linhagem luminosa que temos rastreado:

\author{
¡Oh Áglae, señora, \\ Y tú Eufrósina, de canciones amiga, hijas del más poderoso \\ de los dioses, oídme benévolas ahora, y también tú, Talía, \\ que amas los cantos, mientras este cortejo contemplas
}

Heródoto, Unifesp, Guarulhos, v. 4, n. 1, 2019.1 p. 196-212

DOI: https://doi.org/10.34024/herodoto.2019.v4.10111 
que ligero camina (danza) con motivo de la buena fortuna!

As três se caracterizam por adjetivos amigáveis que acentuam as marcas luminosas do coletivo, ao mesmo tempo em que corroboram o amor pelo canto e pela dança, como Eufrósina, de canções amigas, ou a própria Talía, que adora cantar e andar levemente no mesmo sentido que dança, confirmando mais uma vez uma dimensão funcional que os associa às Musas, amantes do canto e da dança, que formam corais bonitos com o Pai, adornando o Olimpo.

\section{A associação com a beleza}

Embora tenhamos percorrido até aqui um caminho que podemos localizar no tópos da beleza, existe uma função específica em torno da beleza do corpo que também as tem como protagonistas.

Hesíodo e Homero percebem essa dimensão funcional que as associa ao charme e ao amor. Como Bermejo Barrera aponta "En los poemas homéricos sus actividades son fundamentalmente dos: el tejido de las telas y el cuidado corporal, y la danza y el canto en un choros. Y por estas dos actividades se vinculan estrechamente a Afrodita" (Barrera, 1996: 65). O canto VIII da Odiseia alude a essa nova dimensão que colocamos em circulação. Quando a risonha Afrodite partiu para Pafo de Chipre onde seu altar coroado com oferendas está localizado, "na chegada, ela foi lavada pelas Graças, ungida com óleo imortal, que brilha na pele dos deuses eternos, e vestida com roupas preciosas, feitiço dos olhos" (Od. VIII, 362366).

Os versos, sem dúvida, evocam o dispositivo ritual de adornar Pandora como a primeira noiva do Ocidente (Leduc, 1992), onde as Graças também participam, como veremos em breve. Homero as apresenta em uma função que reforça a feminilidade do coletivo. São elas que, associadas ao encanto e à beleza, adornam Afrodite. É uma nova vantagem da sema dominante de charme e sedução. Assim como cantar e dançar produzem prazer, da mesma forma, a beleza feminina constitui um "feitiço nos olhos". Banhos, óleos imortais e roupas preciosas formam o enredo de um ritual feminino onde a sedução e o amor são ensinados.

Assim, se pensarmos na linha de continuidade em torno do tema do encanto, Trabalhos e Dias, se refere a elas quando se trata de embelezar Pandora no âmbito do ritual que adorna a primeira mulher. São elas que coroam a Pandora com flores, segundo Hesíodo, nestes termos:

\footnotetext{
${ }^{8}$ Píndaro, Olímpica XIV

Heródoto, Unifesp, Guarulhos, v. 4, n. 1, 2019.1 p. 196-212

DOI: https://doi.org/10.34024/herodoto.2019.v4.10111
} 


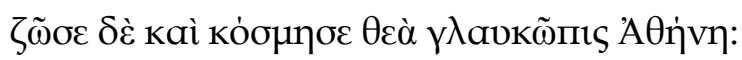

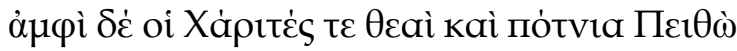

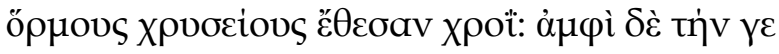

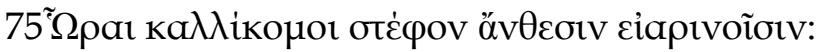

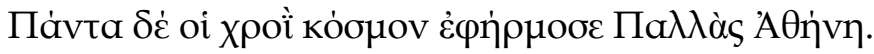

"le dio vida y la adornó la diosa de ojos glaucos Atenea;

Las Cárites divinas y la augusta Peito

en torno de su cuerpo colocaron collares dorados; y a su alrededor

las Horas de hermosos cabellos la coronaron con flores primaverales;

todo el ornato a su cuerpo aplicó Palas Atenea" (Trabajos y días, 75).

De fato, são as divinas Khárites, Xápı $\varepsilon \dot{s} \theta$ $\theta \alpha a ̀$, responsáveis por colocar as belas jóias que adornam a noiva, um ritual presidido por Atena. A presença

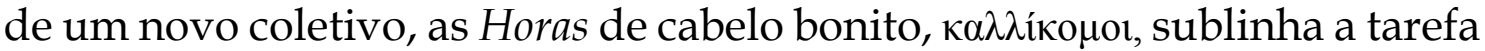
cosmética de coroá-la com belas flores da primavera.

Pensemos nelas como um atalho breve que ajuda a ler a valência positiva de certos coletivos relacionados dentro da estrutura do dispositivo mítico como lógos explicativos que obedecem a uma intricada arquitetura de significado. É claro observar a imagem para associar iconograficamente uma semelhança com os coletivos femininos que temos analisado.

Antes de sua aparição na Teogonía Hesíódica, as Horas já aparecem na Ilíada como guardiãs das portas do Olimpo, uma porta que se abre e se fecha para recolher ou dispersar as nuvens. Eles são divindades sorridentes que presidem tudo o que chega ao seu tempo, como uma fruta madura que cai da árvore no momento certo. Lá estão elas, no casamento de Tetis e de Peleo; elas também guardam o crescimento da vegetação, porque eles simbolizam fenômenos naturais e normalmente, como as Graças, daqueles que são muito próximos por características semelhantes, aparecem dançando. Regulam o nascimento e o casamento, mas não a morte, porque estão sempre presentes em momentos felizes.

Marcas de identidade continuam a bordar uma experiência festiva, começando não apenas com canto e dança, mas com um certo modelo de instalação na economia geral do pensamento mítico. Musas, Khárites e Horas respondem a essa necessidade do Olimpo de ter uma parcela de

Heródoto, Unifesp, Guarulhos, v. 4, n. 1, 2019.1 p. 196-212

DOI: https://doi.org/10.34024/herodoto.2019.v4.10111 
juventude e beleza que preencherá as moradas olímpicas com encanto e felicidade.

\section{Considerações finais}

O presente trabalho consistiu em primeiro lugar em rever a função do discurso mítico na produção de Hesíodo para pensá-lo como um operador que institui um universo de sentido como um efeito da verdade e que está em uma zona ambígua de caminhos entrelaçados entre a estrutura de mito e filosofia.

Neste contexto, tentamos destacar a figura das Khárites que, a partir de certas marcas identitárias e funcionais, acabou por ser associada às Musas; essa associação nos permitiu traçar formas de poder feminino, lidas a partir de um certo tipo de conhecimento que se desdobra em suas ações. Assim, nos detemos nas Khárites para colocá-las naquele bosque mítico dentro do discurso hesiódico e além dele, territorializando-as no cenário daquela lógica de linhagem, a corresponder-lhes um escopo diurno daquelas marcas identitárias. Poderes ligados à beleza, encanto, sedução e amor foram o alvo para o qual direcionamos nossa análise.

Nós começamos com a proximidade do espaço. De fato, conforme analisamos, as Khárites têm suas casas ao lado das delicadas filhas de Zeus, Himerus e Desejo, desenhando os mesmos tipos de elementos que abrigam elementos de valoração positiva.

Nos detivemos na análise de Bermejo Barrera para pensar sobre a chave da associação proposta pelo autor entre os dois coletivos, posição com a qual concordamos, e ver a predominância da função comemorativa como aquela dimensão que os combina em uma instalação comum dentro da economia mítica. Sua ligação com o poder e o conhecimento é a condição de uma força matricial feminina a serviço da conservação e do cuidado da ordem cósmica. Se posteriormente no nível da poesia como função sócio religiosa, o poeta inspirado se estabelecerá como um "oficial de soberania", nesse nível da história mítica, o coletivo feminino cumpre uma função orientadora e análoga, servindo com sua voz divina, öooa, para Zeus, o fiador da ordem cósmica, aquele que representa o princípio da inteligibilidade de uma legalidade que encontra sua materialidade na canção divina.

Em seguida, nos propusemos a passar outro testemunho sobre as Khárites para corroborar algumas características identitárias e funcionais que a narrativa de Hesíodo havia exibido. Para tal projeto, trabalhamos a XIV Olímpica de Píndaro, uma obra em que o poeta fala louvável e 
amorosamente às deusas. A relação estrutural com as Musas é claramente atestada na função de comemoração que as associa e as familiariza em uma pegada identitária idêntica.

Khárites e Musas estão inscritos na mesma linhagem diurna a partir de sua clareza, daquela exuberância de ternura, doçura e alegria, que derrama abundantemente e é característico de sua condição genealógica como sendo filhas de um Pai glorioso e de mães relevantes.

Embora o trabalho se movesse predominantemente no tópos da beleza, também cobrimos uma função específica em torno da beleza do corpo que os tem como protagonistas. Tanto Hesíodo quanto Homero percebem essa dimensão funcional que os associa a encanto e amor. Musas, Khárites e até mesmo as Horas respondem a essa necessidade política do dispositivo olímpico de ter uma parte doce da juventude, beleza, encanto e sedução que enche as moradas dos Imortais de felicidade.

\section{Referencias bibliográficas}

BARRERA BERMEJO, Juan Carlos, GONZÁLEZ GARCÍA, Francisco Javier, REBOREDA MORILLO, Susana. Los orígenes de la mitología griega. Madrid: Akal, 1996.

BRANDAO, Jacyntho Lins. Antiga Musa (Arqueología da fiç̧ão). Belo Horizonte: FALE, 2005.

CALAME, C. Eros en la antigua Grecia, Madrid, Akal, 2002.

COLOMBANI, María Cecilia. Hesíodo. Discurso y Linaje. Una aproximación arqueológica. Mar del Plata: EUDEM, 2016.

DETIENNE, Marcel. Los maestros de verdad en la Grecia Arcaica. Madrid: Taurus, 1986.

FOUCAULT, Michel. "Entrevista sobre la prisión: el libro y su método". En: Idem. Microfísica del poder., Madrid: Ediciones La Piqueta, 1979.

HESÍODO. Obras y fragmentos. Gredos, Madrid. 2000

HESIOD. Theogony. Works and Days. Testimonia. Most, G. W. Loeb Classical Library. London: Harvard University Press, 2006.

HOMERO. Odisea. Madrid: Gredos, 2000.

JAEGER, Werner. Paideia. México: Fondo de Cultura Económica, 1995. 
LEDUC, Claudine. “¿Cómo darla en matrimonio? La novia en Grecia, siglos IX-IV a. C.". En: Duby, George, Perrot, Michelle. Historia de las Mujeres, 1. La Antigüedad, Madrid: Taurus, 1992.

LIDDEL, H. G., SCOTT, R. A Greek-English Lexicon. Oxford: Clarendon Press, 1996.

LIÑARES, Lucía. Teogonía, Trabajos y Días. Edición bilingüe. Buenos Aires: Losada, 2005.

RODRÍGUEZ ADRADOS, F. (2001) "La composición de los poemas hesiódicos", EMÉRITA, Revista de Lingüística y Filología Clásica. LXIX, 2, 2001, pp. 197-223.

VIANELLO DE CÓRDOVA, Paola. Teogonía. México: Universidad Nacional Autónoma de México, 1978. 